\title{
Wheat straw hemicellulose films as affected by citric acid
}

\author{
Henriette M.C. Azeredo a, ${ }^{*}$, Charis Kontou-Vrettou ${ }^{\mathrm{b}}$, Graham K. Moates ${ }^{\mathrm{c}}$, \\ Nikolaus Wellner ${ }^{c}$, Kathryn Cross ${ }^{c}$, Paulo H.F. Pereira ${ }^{c}$, Keith W. Waldron ${ }^{c}$ \\ ${ }^{a}$ Embrapa - Secretariat for International Affairs, Edifício Embrapa Sede, Prédio CECAT, $3^{\circ}$ andar, Parque Estação Biológica, Av. W3 Norte, Brasília, DF, \\ CEP 70770-901, Brazil \\ ${ }^{\mathrm{b}}$ Agricultural University of Athens, Iera Odos 75, 11855, Athens, Greece \\ ${ }^{\mathrm{c}}$ Institute of Food Research, Norwich Research Park, Colney, Norwich, NR4 7UA, UK
}

\section{A R T I C L E I N F O}

\section{Article history:}

Received 4 September 2014

Received in revised form

23 February 2015

Accepted 5 April 2015

Available online 14 April 2015

\section{Keywords:}

Food packaging

Polysaccharides

Biopolymers

Biodegradable films

Crosslinking

\begin{abstract}
A B S T R A C T
Hemicelluloses have been extracted from wheat straw with an alkaline peroxide solution. Biodegradable films intended for food packaging have been produced from hemicelluloses mixed with glycerol and different concentrations of citric acid (as a crosslinking agent), with or without sodium hypophosphite (catalyst to the crosslinking reaction). A curing treatment at $150{ }^{\circ} \mathrm{C}$ has been carried out on the dried films in order to promote formation of ester bonds between citric acid and hemicelluloses. The crosslinking reaction, evidenced by FTIR spectra, improved water resistance and water vapor barrier properties of the films. On the other hand, the citric acid effects on film tensile properties were more consistent with those of a plasticizer than of a crosslinker, which might be ascribed to a flexible crosslinking. Sodium hypophosphite (SHP) did not affect the properties of crosslinked films. FTIR spectra indicated that some crosslinking reaction occurred even in a non-cured film.
\end{abstract}

() 2015 Elsevier Ltd. All rights reserved.

\section{Introduction}

In the last decades, an increasing interest from research institutes and industries in biopolymers from renewable sources is noticeable, and has been motivated by shortage of natural energy sources as well as the necessity of replacement of petroleum-based products, which is connected with demands for more environmentally friendly materials. In 2011, the global use of biodegradable plastics was 0.85 million metric tons. BCC Research recorded a global bioplastic demand of 1.1 million metric tons in 2013, expected to reach 1.4 million metric tons in 2014 and about 6 million metric tons in 2019, in a compound annual growth rate of $32.7 \%$ (BCC, 2014). According to studies by Helmut Kaiser Consultancy (2013), bioplastics are expected to cover approximately 25-30\% of the total plastics market by 2020 .

The worldwide wheat consumption has been estimated to be around 705 million tons in 2013/2014 (WASDE, 2014). Wheat straw and bran, which are abundant co-products of wheat crop, represent a valuable source of hemicelluloses, cellulose and lignin. In the European Union, some millions of tons of wheat straw and wheat

\footnotetext{
* Corresponding author.

E-mail address: henriette.azeredo@embrapa.br (H.M.C. Azeredo).
}

bran could be collected per year (Martel, Estrine, Plantier-Royon, Hoffmann, \& Portella, 2010). Some of those co-products are used in animal feed and paper production, but the majority is discarded as waste, when it could be exploited to produce high-valued materials such as biodegradable (or edible) films for food packaging.

The hydrophilic nature of polysaccharide films provide them with good oxygen barrier properties, but their water vapor barrier and moisture resistance are poor (Giancone et al., 2011; Janjarasskul \& Krochta, 2010). A high water solubility obviously affects the applicability of edible films, since a packaging material is not supposed to dissolve upon contact with water. Another problem which can result from polysaccharide hydrophilicity is swelling by water, leading the films to have their mechanical and overall barrier properties impaired (Sebti, Delves-Broughton, \& Coma, 2003). The water resistance of a film can be improved by crosslinking, which consists of linking polymer chains by covalent (chemical crosslinking) or by weaker bonds (physical crosslinking), forming three-dimensional networks which reduce the mobility of the structure, usually enhancing its water resistance (reducing both water solubility and swelling by water) as well as its mechanical and barrier properties (Balaguer, Gómez-Estaca, Gavara, \& Hernandez-Muñoz, 2011).

Dicarboxylic and polycarboxylic acids such as citric acid have been reported by several authors (Bonilla, Talón, Atarés, Vargas, \& 
Chiralt, 2013; Coma, Sebti, Pardon, Pichavant, \& Deschamps, 2003; Möller, Grelier, Pardon, \& Coma, 2004; Olsson, Hedenqvist, Johansson, \& Järnström, 2013) to act as crosslinking agents for polysaccharide films. One advantage of citric acid is that any unreacted acid is not only nutritionally acceptable but it can also act as a plasticizer (Chabrat, Abdillahi, Rouilly, \& Rigal, 2012; Shi et al., 2008). The crosslinking mechanism is attributed to covalent intermolecular di-ester linkages between hydroxyl groups of the polysaccharide and two carboxyl groups of the crosslinker (Coma et al., 2003; Hashem, Sharaf, El-Hady, \& Hebeish, 2013; Olsson, Hedenqvist, et al., 2013), as indicated in Fig. 1. In a first step (not shown in Fig. 1), carboxyl groups of the acid form cyclic anhydrides, which react further with the carbohydrate hydroxyls (Xiaohong \& Yang, 2000). The reaction has been reported to be favored by a high temperature (typically above $100{ }^{\circ} \mathrm{C}$ ) curing process on the dried films (Coma et al., 2003; Dastidar \& Netravali, 2012; Olsson, Hedenqvist, et al., 2013, Olsson, Menzel, et al., 2013), although the crosslinking reaction has also been reported to take place at a relatively low temperature $\left(70{ }^{\circ} \mathrm{C}\right.$ ) by Menzel et al. (2013). Sodium hypophosphite (SHP) acts as a catalyst for the reaction (Reddy \& Yang, 2010; Salam, Pawlak, Venditti, \& El-tahlawy, 2011) by weakening the hydrogen bonding between the carboxylic acid groups (Xiaohong \& Yang, 2000), increasing the speed of formation of the cyclic anhydride intermediate (Feng, Xiao, Sui, Wang, \& Xie, 2014; Garcia et al., 2014; Sauperl \& Stana-Kleinschek, 2010) and allowing the reaction to occur at a lower temperature (Feng et al., 2014). Peng, Yang, and Wang (2012), when studying maleic acid crosslinking in cotton fabrics, suggested that SHP reacted to two maleic acid molecules already esterified with cellulose, forming a new crosslink between two cellulose molecules.

A previous study (Ruiz et al., 2013) has shown wheat straw hemicelluloses as a promising reinforcement material to $\kappa$-carrageenan/locust bean gum blend films. However, no previous study has been found describing the use of wheat straw hemicelluloses as a film matrix.

The objectives of this study were to evaluate some physical properties of films from wheat straw hemicelluloses as affected by citric acid contents, the presence of sodium hypophosphite and the curing step.

\section{Materials and methods}

\subsection{Isolation of hemicelluloses}

Wheat straw was milled to less than $0.5 \mathrm{~mm}$ in a Retsch Brinkmann ZM-1 centrifugal grinding mill (Retsch GmbH, Haan, Germany). The hemicellulose and $\alpha$-cellulose contents of milled wheat straw were analyzed (in triplicate) as described by TAPPI
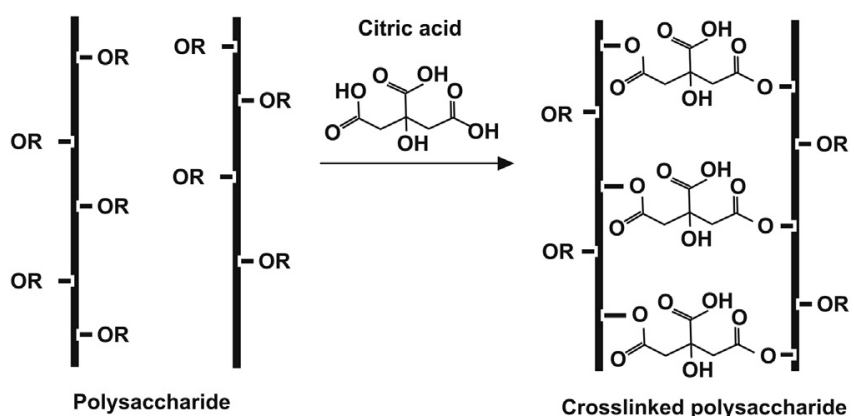

Fig. 1. Proposed mechanism for covalent crosslinking between citric acid and a polysaccharide.

Adapted from Hashem et al. (2013).
T203 cm-99 (TAPPI, 2009), and holocellulose, according to Yokoyama, Kadla, and Chang (2002).

$100 \mathrm{~g}$ of milled straw were washed with $1 \mathrm{~L}$ of $0.2 \%(\mathrm{w} / \mathrm{v})$ ethylenediamine tetraacetic acid (EDTA) solution at $90{ }^{\circ} \mathrm{C}$ for $1 \mathrm{~h}$, to remove water soluble components and to chelate hydrogen peroxide $\left(\mathrm{H}_{2} \mathrm{O}_{2}\right)$ decomposing metals. The hemicelluloses were extracted with an alkaline $\mathrm{H}_{2} \mathrm{O}_{2}$ solution $(2 \% \mathrm{w} / \mathrm{v}, \mathrm{pH}$ adjusted to 12.5 with potassium hydroxide) for $16 \mathrm{~h}$ at $50{ }^{\circ} \mathrm{C}$, following the conditions as optimized by Fang, Sun, Salisbury, Fowler, and Tomkinson (1999) for hemicellulose extraction of wheat straw. The $\mathrm{H}_{2} \mathrm{O}_{2}$ was used to delignify the material, since preliminary tests indicated that films from non-delignified hemicelluloses (extracted by using $\mathrm{KOH}$ solutions in different concentrations) were cracking, not continuous structures. During an alkaline $\mathrm{H}_{2} \mathrm{O}_{2}$ treatment, the peroxide degrades in a reaction with the hydroperoxide anion $\left(\mathrm{HOO}^{-}\right)$, producing the highly reactive hydroxyl radical $(\mathrm{HO} \cdot)$ which oxidizes lignin forming low molecular weight, water-soluble products (Fang et al., 1999).

The supernatant resulting from the subsequent centrifugation was vacuum filtered and its $\mathrm{pH}$ was adjusted to 5.0 with acetic acid. Ethanol was added to a concentration of $60 \%$, the suspension was stirred for $30 \mathrm{~min}$, left overnight at $4{ }^{\circ} \mathrm{C}$, centrifuged, washed with ethanol $70 \%$, centrifuged again, and left to dry at room temperature. The dried hemicelluloses were then milled to a fine powder by using a basic mill (A10, IKA GmbH, Germany).

\subsection{Film formation}

The hemicellulose powder was homogenized for $15 \mathrm{~min}$ in distilled water $(5 \mathrm{~g} / 100 \mathrm{~mL})$ with $30 \%$ glycerol $(\mathrm{w} / \mathrm{w}$, on a hemicellulose basis), citric acid $(5 \%, 10 \%, 20 \%$, or $30 \% \mathrm{w} / \mathrm{w}$ on a hemicellulose basis), with or without SHP ( $50 \% \mathrm{w} / \mathrm{w}$ on a citric acid basis), by using a homogenizer (Ystral X10/25, BallrechtarDottingen, Germany). Air bubbles were removed under vacuum, and the films were cast on petri dishes to a final dried thickness of $0.09 \mathrm{~mm}$, left to dry at room temperature for $24 \mathrm{~h}$, then conditioned $\left(50 \% \mathrm{RH}, 24{ }^{\circ} \mathrm{C}\right.$ ) in an environmental chamber (Weiss Gallenkamp, Loughborough, UK) for $24 \mathrm{~h}$, so they had all similar moisture contents (between 11.91 and $12.32 \mathrm{~g} / 100 \mathrm{~g}$ ). The dried films were then subjected to a curing treatment at $150{ }^{\circ} \mathrm{C}$ for 10 min using a fan oven (Memmert, Schwabach, Germany). Apart from a control film (with no citric acid or SHP), three groups of films were prepared, namely, CA-C (those added with citric acid and cured), CA-NC (added with citric acid and not subjected to the curing treatment), and CA-C-SHP (added with citric acid and SHP, and cured).

The water vapor permeability (WVP) determination was modified from the method E96-05 (ASTM, 2005) for five circular samples (30 $\mathrm{mm}$ in diameter). The thicknesses of the samples were measured using a micrometer screw gauge (Moore \& Wright, Sheffield, UK) to the nearest $0.01 \mathrm{~mm}$ at 5 random locations, and the average value was calculated. The test films were sealed as patches onto acrylic permeation cells $(2.4 \mathrm{~cm}$ in diameter and $1 \mathrm{~cm}$ in height) containing $2 \mathrm{~mL}$ of distilled water. The cells were placed in a desiccator connected to two channels providing a steady flow of dried air (less than $1 \% \mathrm{RH}$ ) from a Balston $75-60$ air drier at $24^{\circ} \mathrm{C}$, and were weighed 7 times over a 24 -h period.

The water solubility determination was conducted on $2 \mathrm{~cm} \times 2 \mathrm{~cm}$ film pieces in quadruplicate, based on the method proposed by Ojagh, Rezaei, Razavi, and Hosseini (2010), with some modifications. Previously dried and weighed samples were immersed in $50 \mathrm{~mL}$ of distilled water for $6 \mathrm{~h}$ at $25^{\circ} \mathrm{C}$, under stirring (150 rpm). The dry weight of the remaining film pieces was obtained after filtration on previously dried and weighed filter paper, and it was used to calculate the insoluble matter as a percentage of the initial dry weight. All the dry weights (of the initial and final 
film pieces and the filter paper) were determined after drying at $103^{\circ} \mathrm{C}$ for $24 \mathrm{~h}$ using a fan oven (Memmert, Schwabach, Germany).

Tensile tests were conducted on $8 \mathrm{~mm} \times 50 \mathrm{~mm}$ specimens, according to the method D882-09 (ASTM, 2009), on a Texture Analyzer TA.XT Plus (Stable Micro Systems, Godalming, UK), using A/TG Tensile Grips and a $5 \mathrm{~kg}$ load cell, on $50 \mathrm{~mm} \times 8 \mathrm{~mm}$ strip film samples previously conditioned ( $50 \% \mathrm{RH}, 24{ }^{\circ} \mathrm{C}, 48 \mathrm{~h}$ ) in an environmental chamber (Weiss Gallenkamp, Loughborough, UK). The thicknesses of the specimens were determined by using a micrometer screw gauge (Moore \& Wright, Sheffield, UK) to the nearest $0.01 \mathrm{~mm}$ at 5 random locations. The initial grip separation and crosshead speed were set to $40 \mathrm{~mm}$ and $1 \mathrm{~mm} / \mathrm{s}$, respectively. Force $(\mathrm{N})$ and deformation $(\mathrm{mm})$ were recorded during extension. Tensile strength was calculated by dividing the required force for film rupture by the cross-sectional area, and elongation at break was calculated as the percentage increase in sample length. The elastic modulus was calculated from the slope of the stress-strain curve at the elastic deformation region. The reported values correspond to five measurements.

Fourier-transform infrared (FTIR) spectra (128 scans at $2 \mathrm{~cm}^{-1}$ resolution for a spectral range from 4000 to $500 \mathrm{~cm}^{-1}$ ) were recorded using a Digilab FTIR spectrometer equipped with a Digilab UMA 600 microscope (Digilab, Randolph, MA, USA).

The scanning electron microscopy (SEM) images of gold-coated film surfaces were taken using a Zeiss Supra 55 VP SEM (Zeiss, Oberkochen, Germany) with an acceleration voltage of $3 \mathrm{kV}$, and a magnification of $1000 \times$.

\section{Results and discussion}

The holocellulose, $\alpha$-cellulose and hemicellulose contents of the wheat straw and the hemicellulose powder are presented at Table 1. The contents of the wheat straw were similar to those reported by Govumoni, Koti, Kothagouni, Venkateshwar, and Linga (2013). The hemicellulose powder (product of the extraction) contained mostly hemicelluloses (about 87\%), although there were still some $\alpha$-cellulose and about $9 \%$ of other components. Considering that the yield of the extraction process was $18.5 \% \mathrm{w} / \mathrm{w}$ (on a wheat straw dry basis), and taking into account the hemicellulose content of the wheat straw and the hemicellulose powder, the efficiency of the extraction procedure can be estimated as only about $54 \%$.

The film properties as affected by citric acid and SHP are presented in Fig. 2. The most dramatic effect of citric acid was on insoluble matter, which was increased 5-fold by the addition of $20 \%$ citric acid. The water vapor permeability (WVP) tended to decrease accordingly, although not to the same extent. Some previous studies corroborate those changes (Coma et al., 2003; Menzel et al., 2013; Olivato, Grossmann, Bilck, \& Yamashita, 2012; Wang, Ren, Li, Sun, \& Liu, 2014), which are attributed to the ester bonds formed between citric acid and the polysaccharide (Wang et al., 2014), producing a denser structure. Crosslinking interconnects polysaccharide molecules, providing better intermolecular interaction leading to a decreased water uptake (Abdillahi, Chabrat, Rouilly, \& Rigal, 2013). The reduced polymer chain mobility probably made

Table 1

Holocellulose, $\alpha$-cellulose and hemicellulose contents (on a dry weight basis) of the wheat straw and the hemicellulose powder (values represented as mean \pm standard deviation).

\begin{tabular}{llc}
\hline Fractions & Milled wheat straw & Hemicellulose powder \\
\hline Holocellulose (\%) & $62.52 \pm 0.86$ & $91.21 \pm 0.74$ \\
$\alpha$-cellulose (\%) & $32.62 \pm 1.63$ & $4.14 \pm 0.17$ \\
Hemicelluloses (\%) & $29.90 \pm 0.96$ & $87.06 \pm 0.79$ \\
\hline
\end{tabular}

the water diffusion more difficult, explaining the reduced WVP (Olivato et al., 2012). The reduced availability of hydroxyl groups and their substitution by hydrophobic ester groups could also contribute to the citric acid content effects on WVP and water solubility (Ghanbarzadeh, Almasi, \& Entezami, 2011; Ma, Jian, Chang, \& Yu, 2008).

Some studies have reported citric acid effects on films only as a crosslinking agent (Olivato et al., 2012; Reddy \& Yang, 2010; Reddy, Jiang, \& Yang, 2012), while others have reported it to act only as a plasticizer (Abdillahi et al., 2013; Chabrat et al., 2012). However, the present study presented both effects apparently coexisting, although apparently inconsistent to each other. On the one hand, citric acid addition decreased tensile strength and modulus, and increased elongation when at 10\% (and at higher concentrations for films with SHP), reflecting the behavior of a plasticizer instead of a crosslinking agent. On the other hand, the water solubility and the WVP tended to decrease with citric acid - the soluble matter increasing typically up to $20 \%$ citric acid, and the WVP tending to decrease up to $20 \%$ citric acid (except for film with SHP, whose WVP did not significantly change). Some other studies reported similar findings (Sebti et al., 2003; Shi et al., 2008; Wang et al., 2014). Wang et al. (2014) observed that citric acid contents higher than $10 \%$ in polyvinyl alcohol/xylan films resulted in plasticizing effects evidenced from tensile tests, while the water vapor permeability of the films kept decreasing with increasing citric acid contents, consistent with a crosslinking effect, suggesting coexisting crosslinking and plasticizing effects of citric acid. The plasticizing effect of citric acid was attributed to increasing interstitial volume of the film or increasing molecular mobility, making the polymeric networks less dense (Wang et al., 2014). In the present study, although citric acid impaired strength and modulus, it improved the toughness (which represents the energy required for the sample to break), corroborating results by Reddy, Li, and Yang (2009). A possible explanation for this apparently inconsistent behavior is that citric acid might act as a flexible crosslinker. Some previous studies (Hu, Song, Liu, \& Zhang, 2010; Jia, Zhang, He, \& Ning, 2005; Zhang, Hu, Jia, \& Du, 2003) have described that, although chemical crosslinking usually imposes constraints on the motion of chain segments, a flexible crosslinking agent may act similarly to a plasticizer. The flexibility of citric acid crosslinking might then explain why it was effective in reducing the film solubility and WVP while impairing the overall tensile properties.

Although SHP has been mentioned as an effective catalyst for the crosslinking reaction of polysaccharides with citric acid (Feng et al., 2014; Reddy \& Yang, 2010; Xiaohong \& Yang, 2000), some studies (Coma et al., 2003; Feng et al., 2014) reported a lack of effect of SHP as a catalyst for citric acid crosslinking. On the other hand, the present study indicates that SHP had the opposite effect (especially at higher citric acid contents), decreasing strength and modulus, increasing elongation, and increasing WVP, indicating that its presence actually impaired the crosslinking effects of citric acid, which might be explained by its diluting effects on the reagents (citric acid and hemicelluloses).

The non-cured films (CA-NC) presented tensile properties almost identical to those of the corresponding cured films (CA-C). Their only differences when compared to cured films were that their insoluble matter was lower, and, accordingly, their WVP was slightly higher. So, although the curing treatment has improved the water resistance of the crosslinked films, some crosslinking seems to have occurred even in non-cured films.

Fig. 3 shows the Fourier transform infrared (FTIR) spectra of the control film (CA0) and films with 30\% citric acid (CA30-C, CA30-CSHP, and CA30-NC). The peak at $1717 \mathrm{~cm}^{-1}$ and the shoulder at $1695 \mathrm{~cm}^{-1}$ are ascribed to free and hydrogen bonded carboxylic acid groups, respectively. This area is less intense in CA30-C-SHP 

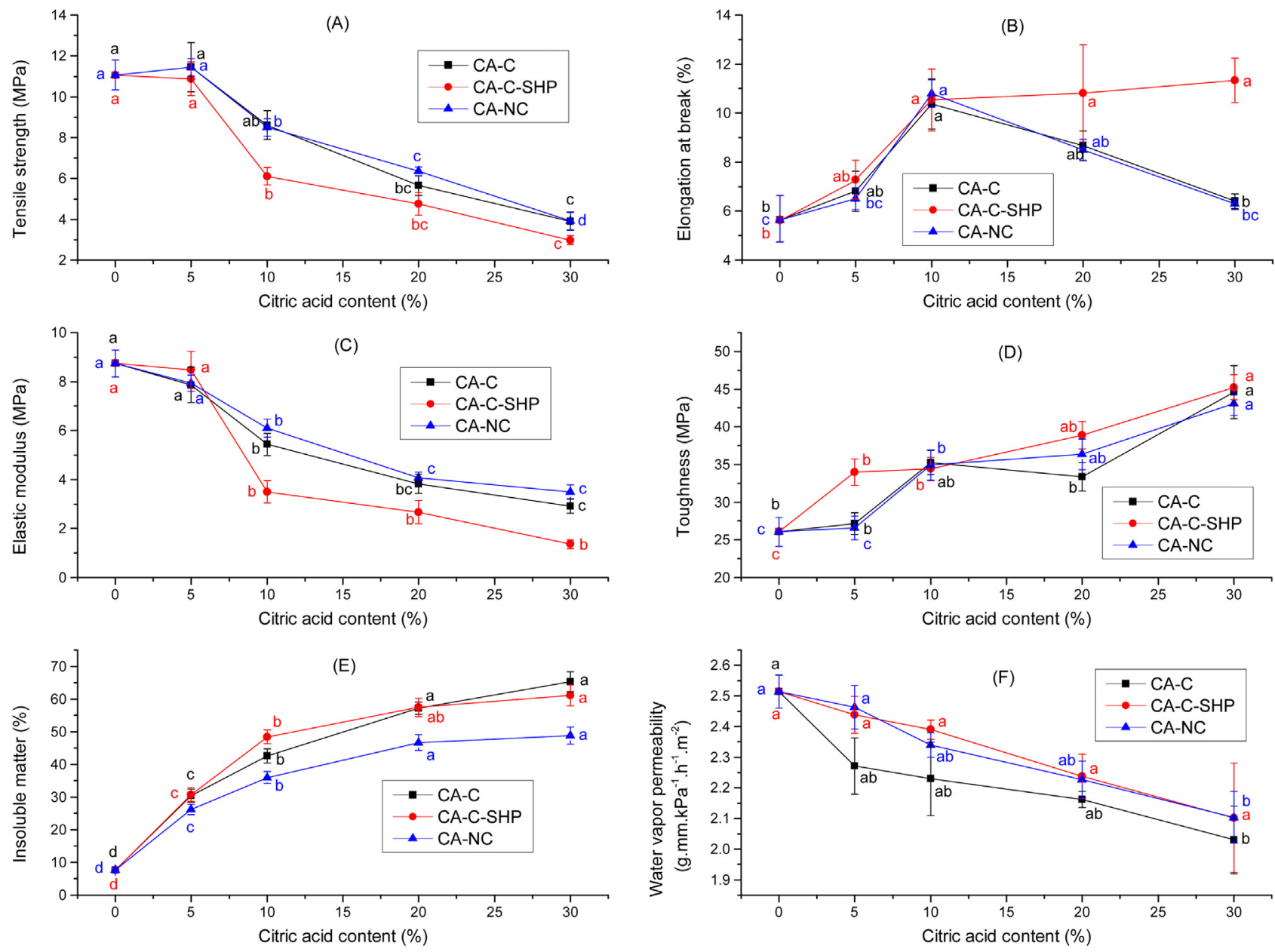

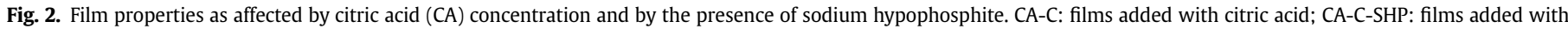

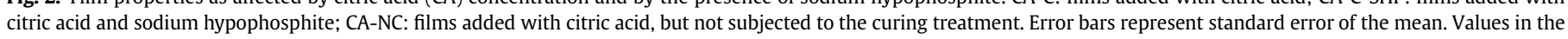
same line labeled with the same letter are not significantly different (Tukey, $p<0.05$ ).

than in CA30-C film, indicating that SHP could have promoted citric acid decarboxylation on curing, as suggested by Yao, Wang, Ye, and Yang (2013), which would explain the unexpected effects of SHP on tensile properties and WVP of films in the present study. The

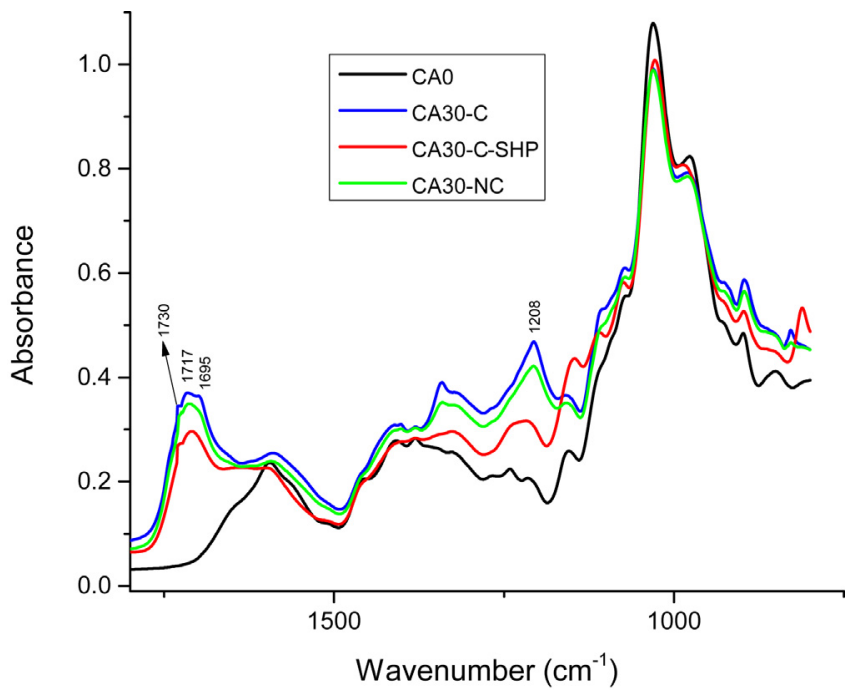

Fig. 3. FTIR spectroscopy of films: CA0 (control), CA30-C (30\% citric acid, cured), CA30C-SHP (30\% citric acid + 15\% SHP, cured), and CA30-NC (30\% citric acid, non-cured). increased peak at $1208 \mathrm{~cm}^{-1}$ in films with citric acid is ascribed to $\mathrm{C}-\mathrm{O}$ stretching of formed ester bonds (Bagheri, Yarmand, Madadlou, \& Mousavi, 2014; Groen \& Roberts, 2001; Rhim et al., 2004). The presence of ester bonds may be indicated by the presence of a small shoulder around $1730 \mathrm{~cm}^{-1}$ in films with citric acid (Coma et al., 2003), which corresponds to ester $\mathrm{C}=\mathrm{O}$ stretching vibration (Dastidar \& Netravali, 2012; Shi et al., 2007; Wang et al., 2014). Interestingly, this shoulder is evident even in the noncured film, indicating again that some crosslinking may have taken place even at room temperature, corroborating the results of insoluble matter and WVP (Fig. 2E and F). Previously to this study, the lowest temperature at which the crosslinking reaction of citric acid with a polysaccharide has been reported to take place was $70{ }^{\circ} \mathrm{C}$ (Menzel et al., 2013). Moreover, the presence of SHP did not enhance this peak, suggesting that SHP did not affect the crosslinking reaction, corroborating our previous observations on physical properties of the films. The presence of SHP did not change noticeably the spectra.

The curing process probably favored not only crosslinking but also some degree of hydrolysis of the glycosidic bonds in hemicelluloses (especially with higher citric acid contents), which has been previously reported to occur in starch (Menzel et al., 2013; Olivato et al., 2012; Shi et al., 2007). However, the decreasing water solubility of the films with increasing citric acid contents (Fig. 2F) suggests that the hydrolysis effect was less noticeable than the crosslinking effect. 

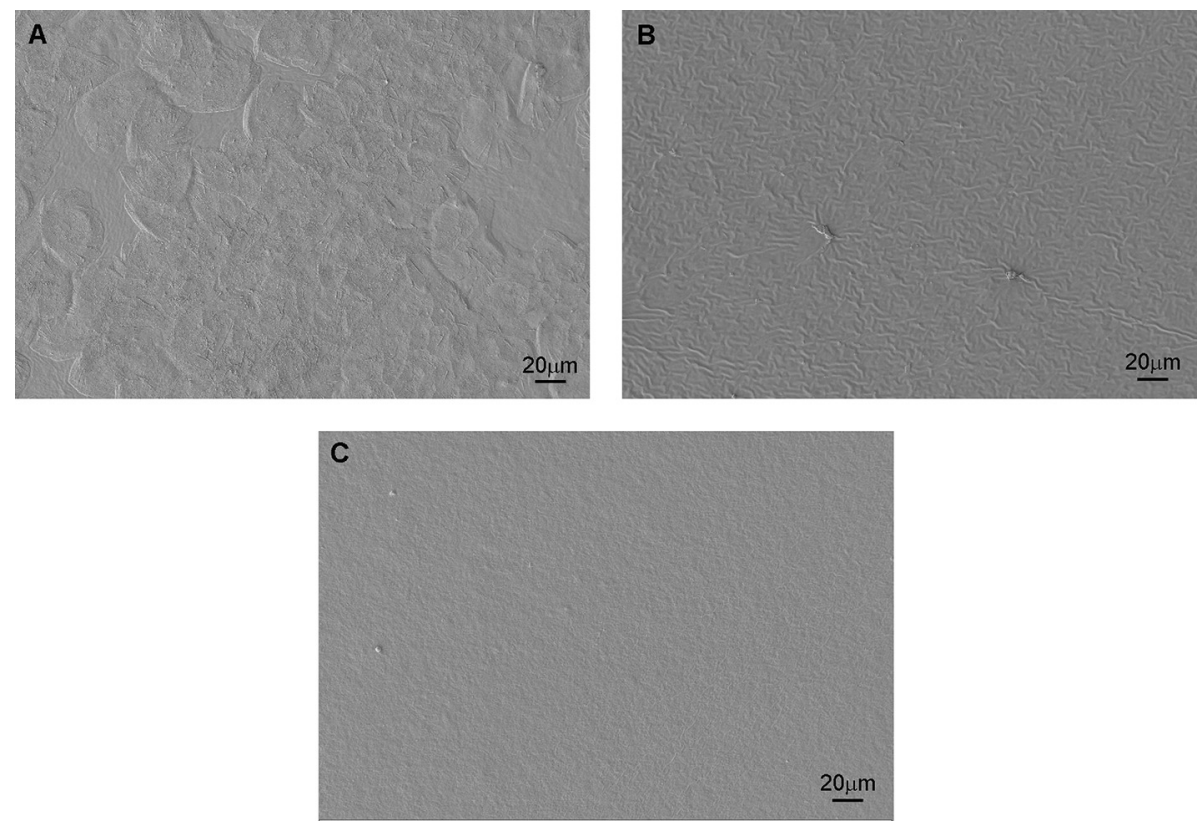

Fig. 4. SEM images of films with $30 \%$ citric acid without SHP (A) or with SHP (B), and the control (C).

Glycerol (which was used as a plasticizer) can easily react with citric acid, competing with hemicelluloses, which could eventually impair the crosslinking. On the other hand, Yao et al. (2013) reported that glycerol and other polyols may act as crosslinking extenders, rather facilitating the crosslinking reaction. A study evaluating the effects of varying glycerol contents on crosslinked film properties would be worth investigating.

The SEM images (Fig. 4) reveal that, while the control sample (C) was relatively smooth, the samples with citric acid (A and B) presented textured surfaces, corroborating Bonilla et al. (2013), who observed that the presence of citric acid promoted a coarser surface on starch-chitosan films. The surface texture appears like crystals (probably citric acid crystals) on the sample without SHP (A), but like ripples on the sample with SHP (B). The ripples may be due to the curing treatment, and they may have been masked by the crystals on the sample without SHP. On the other hand, SHP may have favored the citric acid to be more involved in crosslinkings (and less apparent as crystals), although the other results do not corroborate this hypothesis. Alternatively, SHP may have favored dissolution of citric acid crystals by increasing $\mathrm{pH}$, or simply diluted the citric acid crystals, making them less apparent.

\section{Conclusions}

Films were successfully formed using hemicelluloses extracted from wheat straw as a matrix. Citric acid acted as a crosslinker, which was evidenced by its decreasing effects on water solubility and water vapor permeability, and also as a plasticizer, which was evident from its effects on tensile properties. Those apparently contradictory effects might be explained by a flexible crosslinking. No evidence was found for the effectivity of sodium hypophosphite as catalyst for the crosslinking reaction. FTIR spectroscopy suggested that some crosslinking reaction probably took place even in a non-cured film, suggesting that the reaction may have occurred even at room temperature.

\section{Acknowledgments}

The authors gratefully acknowledge the financial support of the UK Biotechnology \& Biological Sciences Research Council (BBSRC,
Reference Number BBS/E/F/00042712) and the Brazilian Agricultural Research Corporation (Embrapa). Authors also thank the National Counsel of Technological and Scientific Development (CNPq, Brazil) for the Research Productivity Fellowship (304179/2012-4) granted to H.M.C. Azeredo, and for the scholarship granted to P.H.F. Pereira (243244/2013-4).

\section{References}

Abdillahi, H., Chabrat, E., Rouilly, A., \& Rigal, L. (2013). Influence of citric acid on thermoplastic wheat flour/poly(lactic acid) blends. II. Barrier properties and water vapor sorption isotherms. Industrial Crops and Products, 50, 104-111.

ASTM. (2005). Standard test methods for water vapor transmission of materials. E96-05. In Annual book of ASTM standards. Philadelphia: American Society for Testing and Materials.

ASTM. (2009). Standard test method for tensile properties of thin plastic sheeting. D882-09. In Annual book of ASTM standards. Philadelphia: American Society for Testing and Materials.

Bagheri, L., Yarmand, M., Madadlou, A., \& Mousavi, M. E. (2014). Transglutaminaseinduced or citric acid-mediated cross-linking of whey proteins to tune the characteristics of subsequently desolvated sub-micron and nano-scaled particles. Journal of Microencapsulation, 31, 636-643.

Balaguer, M. P., Gómez-Estaca, J., Gavara, R., \& Hernandez-Muñoz, P. (2011). Functional properties of bioplastics made from wheat gliadins modified with cinnamaldehyde. Journal of Agricultural and Food Chemistry, 59, 6689-6695.

BCC Research. (2014). Global markets and technologies for bioplastics. Report code PLS050C. Available at http://www.bccresearch.com/market-research/plastics/ bioplastics-pls050c.html Accessed 24.07.14.

Bonilla, J., Talón, E., Atarés, L., Vargas, M., \& Chiralt, A. (2013). Effect of the incorporation of antioxidants on physicochemical and antioxidant properties of wheat starch-chitosan films. Journal of Food Engineering, 118, 271-278.

Chabrat, E., Abdillahi, H., Rouilly, A., \& Rigal, L. (2012). Influence of citric acid on thermoplastic wheat flour/poly(lactic acid) blends. I: Thermal, mechanical and morphological properties. Industrial Crops and Products, 37, 238-246.

Coma, V., Sebti, I., Pardon, P., Pichavant, F. H., \& Deschamps, A. (2003). Film properties from crosslinking of cellulosic derivatives with a polyfunctional carboxylic acid. Carbohydrate Polymers, 51, 265-271.

Dastidar, T. G., \& Netravali, A. N. (2012). 'Green' crosslinking of native starches with malonic acid and their properties. Carbohydrate Polymers, 90, 1620-1628.

Fang, J. M., Sun, R. C., Salisbury, D., Fowler, P., \& Tomkinson, J. (1999). Comparative study of hemicelluloses from wheat straw by alkali and hydrogen peroxide extractions. Polymer Degradation and Stability, 66, 423-432.

Feng, X., Xiao, Z., Sui, S., Wang, Q., \& Xie, Y. (2014). Esterification of wood with citric acid: the catalytic effects of sodium hypophosphite (SHP). Holzforschung, 68, 427-433.

Garcia, P. S., Grossmann, M. V. E., Shirai, M. A., Lazaretti, M. M., Yamashita, F., Muller, C. M. O., et al. (2014). Improving action of citric acid as compatibiliser in starch/polyester blown films. Industrial Crops and Products, 52, 305-312. 
Ghanbarzadeh, B., Almasi, H., \& Entezami, A. A. (2011). Improving the barrier and mechanical properties of corn starch-based edible films: effect of citric acid and carboxymethyl cellulose. Industrial Crops and Products, 33, 229-235.

Giancone, T., Torrieri, E., Di Pierro, P., Cavella, S., Giosafatto, C. V. L., \& Masi, P. (2011). Effect of surface density on the engineering properties of high methoxyl pectinbased edible films. Food and Bioprocess Technology, 4, 1228-1236.

Govumoni, S. P., Koti, S., Kothagouni, S. Y., Venkateshwar, S., \& Linga, V. R. (2013). Evaluation of pretreatment methods for enzymatic saccharification of wheat straw for bioethanol production. Carbohydrate Polymers, 91, 646-650.

Groen, H., \& Roberts, K. J. (2001). Nucleation, growth, and pseudo-polymorphic behavior of citric acid as monitored in situ by attenuated total reflection Fourier Transform Infrared Spectroscopy. The Journal of Physical Chemistry B, $105,10723-10730$.

Hashem, M., Sharaf, S., El-Hady, M. M. A., \& Hebeish, A. (2013). Synthesis and characterization of novel carboxymethylcellulose hydrogels and carboxymethylcellulolse-hydrogel-ZnO-nanocomposites. Carbohydrate Polymers, 95, 421-427.

Helmut Kaiser Consultancy. (2013). Bioplastics market worldwide 2010/11-20152020-2025. Available at http://www.hkc22.com/bioplastics.html Accessed 24.07.14.

Hu, J.-S., Song, Z.-W., Liu, C., \& Zhang, W.-C. (2010). Influence of different nematic crosslinking unit on mesomorphism of side-chain cholesteric elastomers containing menthyl groups. Colloid and Polymer Science, 288, 851-858.

Janjarasskul, T., \& Krochta, J. M. (2010). Edible packaging materials. Annual Reviews of Food Science and Technology, 1, 415-448.

Jia, Y.-G., Zhang, B.-Y., He, X.-Z., \& Ning, J.-Z. (2005). Synthesis and phase behavior of nematic liquid-crystalline elastomers derived from smectic crosslinking agent. Journal of Applied Polymer Science, 98, 1712-1719.

Ma, X., Jian, R., Chang, P. R., \& Yu, J. (2008). Fabrication and characterization of citric acid-modified starch nanoparticles/plasticized starch composites. Biomacromolecules, 9, 3314-3320.

Martel, F., Estrine, B., Plantier-Royon, R., Hoffmann, N., \& Portella, C. (2010). Development of agriculture left-overs: Fine organic chemicals from wheat hemicellulose-derived pentoses. Topics in Current Chemistry, 294, 79-115.

Menzel, C., Olsson, E., Plivelic, T. S., Andersson, R., Johansson, C., Kuktaite, R., et al. (2013). Molecular structure of citric acid cross-linked starch films. Carbohydrate Polymers, 96, 270-276.

Möller, H., Grelier, S., Pardon, P., \& Coma, V. (2004). Antimicrobial and physicochemical properties of chitosan-HPMC based films. Journal of Agricultural and Food Chemistry, 52, 6585-6591.

Ojagh, S. M., Rezaei, M., Razavi, S. H., \& Hosseini, S. M. H. (2010). Development and evaluation of a novel biodegradable film made from chitosan and cinnamon essential oil with low affinity toward water. Food Chemistry, 122, 161-166.

Olivato, J. B., Grossmann, M. V. E., Bilck, A. P., \& Yamashita, F. (2012). Effect of organic acids as additives on the performance of thermoplastic starch/polyester blown films. Carbohydrate Polymers, 90, 159-164.

Olsson, E., Hedenqvist, M. S., Johansson, C., \& Järnström, L. (2013). Influence of citric acid and curing on moisture sorption, diffusion and permeability of starch films. Carbohydrate Polymers, 94, 765-772.

Olsson, E., Menzel, C., Johansson, C., Andersson, R., Koch, K., \& Järnström, L. (2013). The effect of $\mathrm{pH}$ on hydrolysis, cross-linking and barrier properties of starch barriers containing citric acid. Carbohydrate Polymers, 98, 1505-1513.
Peng, H., Yang, C. Q., \& Wang, S. (2012). Nonformaldehyde durable press finishing of cotton fabrics using the combination of maleic acid and sodium hypophosphite. Carbohydrate Polymers, 87, 491-499.

Reddy, N., Jiang, Q., \& Yang, Y. (2012). Preparation and properties of peanut protein films crosslinked with citric acid. Industrial Crops and Products, 39, 26-30.

Reddy, N., Li, Y., \& Yang, Y. (2009). Wet cross-linking gliadin fibers with citric acid and a quantitative relationship between cross-linking conditions and mechanical properties. Journal of Agricultural and Food Chemistry, 57, 90-98.

Reddy, N., \& Yang, Y. (2010). Citric acid cross-linking of starch films. Food Chemistry, 118, 702-711.

Rhim, J.-W., Park, H. B., Lee, C.-S., Jun, J.-H., Kim, D. S., \& Lee, Y. M. (2004). Crosslinked poly(vinyl alcohol) membranes containing sulfonic acid group: proton and methanol transport through membranes. Journal of Membrane Science, 238, $143-151$.

Ruiz, H. A., Cerqueira, M. A., Silva, H. D., Rodríguez-Jasso, R. M., Vicente, A. A., \& Teixeira, J. A. (2013). Biorefinery valorization of autohydrolysis wheat straw hemicellulose to be applied in a polymer-blend film. Carbohydrate Polymers, 92, 2154-2162.

Salam, A., Pawlak, J. J., Venditti, R. A., \& El-tahlawy, K. (2011). Incorporation of carboxyl groups into xylan for improved absorbency. Cellulose, 18, 1033-1041.

Sauperl, O., \& Stana-Kleinschek, K. (2010). Differences between cotton and viscose fibers crosslinked with BTCA. Textile Research Journal, 80, 383-392.

Sebti, I., Delves-Broughton, J., \& Coma, V. (2003). Physicochemical properties and bioactivity of nisin-containing cross-linked hydroxypropylmethylcellulose films. Journal of Agricultural and Food Chemistry, 51, 6468-6474.

Shi, R., Bi, J., Zhang, Z., Zhu, A., Chen, D., Zhou, X., et al. (2008). The effect of citric acid on the structural properties and cytotoxicity of the polyvinyl alcohol/ starch films when molding at high temperature. Carbohydrate Polymers, 74 $763-770$.

Shi, R., Zhang, Z., Liu, Q., Han, Y., Zhang, L., Chen, D., et al. (2007). Characterization of citric acid/glycerol co-plasticized thermoplastic starch prepared by melt blending. Carbohydrate Polymers, 69, 748-755.

TAPPI. (2009). T $203 \mathrm{~cm}$-99. Alpha-, beta- and gamma-cellulose in pulp.

Wang, S., Ren, J., Li, W., Sun, R., \& Liu, S. (2014). Properties of polyvinyl alcohol/xylan composite films with citric acid. Carbohydrate Polymers, 103, 94-99.

WASDE. (2014). World agricultural supply and demand estimates. WASDE - 531 Available at http://www.usda.gov/oce/commodity/wasde/latest.pdf Accessed 24.07.14.

Xiaohong, X., \& Yang, C. Q. (2000). FTIR spectroscopy study of the formation of cyclic anhydride intermediates of polycarboxylic acids catalyzed by sodium hypophosphite. Textile Research Journal, 70, 64-70.

Yao, W., Wang, B., Ye, T., \& Yang, Y. (2013). Durable press finishing of cotton fabrics with citric acid: enhancement of whiteness and wrinkle recovery by polyol extenders. Industrial and Engineering Chemistry Research, 52, 16118-16127.

Yokoyama, T., Kadla, J. F., \& Chang, H.-M. (2002). Microanalytical method for the characterization of fiber components and morphology of woody plants. Journal of Agricultural and Food Chemistry, 50, 1040-1044.

Zhang, B.-Y., Hu, J.-S., Jia, Y.-G., \& Du, B.-G. (2003). Side-chain cholesteric liquid crystalline elastomers derived from nematic bis-olefinic crosslinking units. Macromolecular Chemistry and Physics, 204, 2123-2129. 